\title{
CANDIDOSE ÚlCERO-VEgetante dA PERNA
}

\author{
Luis Carlos GUCE (1), Walter BELDA JƯNIOR (2) \& Alberto SALEBIAN (3)
}

\section{R E S U M O}

Os Autores apresentam caso de paciente portadora de lesão única, úlcero-vegetante, localizada no 1/3 inferior da perna direita, causada pela Candida albicans. Submetida à terapêtica com Ketoconazol na dose de $400 \mathrm{mg}$ diários durante o primeiro mês de tratamento e $200 \mathrm{mg}$ diários no segundo mês, evoluiu para cura, sem recidiva e com negativação do título de anticorpos anti Candida albicans (fixação do complemento).

UNITERMOS: Candidíase humana - Lesão úlcero-vegetante da perna.

\section{N T ROD U C $\mathrm{X} O$}

Frequentemente a Candida albicans é encontrada de modo saprofítico na cavidade oral, trato gastro-intestinal e secreção vaginal 2,4,9. Esta levedura, entretanto, sob determinadas circunstâncias, é capaz de produzir diversos quadros clínicos, variando do envolvimento superficial da mucosa oral à infecção sistêmica fulminante 1.5,9. Os fatores que mais comumente predispõem à patogenicidade desta levedura são lesões teciduais secundárias à maceraçōes, diabetes melitus descompensada linfomas, leucemias e neoplasias malignas, devendo-se considerar, também, o uso de antibióticos, corticosteróides, drogas antineoplásicas e radioterapia $3,4,6,8$.

A forma úlcero-vegetante é variante pouco comum, causada principalmente pela Candida albicans, raramente observada em paciente adulto, portaçor de placa úlcero-vegetante úniapós o início da terapêtica.

Neste; estudo relatamos casos de paciente ađulto, pфrtador de placa úlcerovegetante úni- ca, causada pela Candida albicans, localizada na perna, e que não apresentava anormalidades imunológicas, tendo evoluído para cura total, sem recidiva do quadro, apos terapêutica com Ketoconazol.

\section{Caso clínico}

L.P.M., 66 anos, branca, feminina, natural de São Paulo, prendas domésitcas, registro HC-230 1311H.

Há 6 meses placa infiltrada, úlcero vegetante, bem delimitada, com numerosas pústu. las na superfície, localizada na face antero-lateral do $1 / 3$ inferior da perna direita (Fig. 1) tendo sido medicada anteriormente com pre. dinisona, ampicilina, rifampicina, iodeto de potássio e infiltrações intralesionais de triancino. lona, sem melhora clínica.

\section{Exames Complementares}

Intradermoreação de Montenegro: negativa;

Trabalho realizado na Divisão de Clinica Dermatologica do Hospital das Clínicas da Faculdade de Medicina da Unìver. sidade de São Paulo (HC/FMUSP) - (Serviço do Prof. Dr. Sebastião A. P. Sampaio). Av. Dr. Enéas de Carvalho Aguiar, 255. CEP 05403 São Paulo, SP, Brasil

(1) Docente da Divisão de Clínica Dermatológica do HC/FMUSP

(2) Auxiliar de Ensino da Divisão de Clínica Dermatológica to HC/FMUSP

(3) Biólogo Micologista do Instituto de Medicina Tropical de São Paulo e do Departamento de Medicina Tropical e Der matologla do HC/FMUSP 
CUCE, L. C.: BELDA JUNIOR, W. \& SALEBIAN, A. - Candidose ulcero-vegetante da perna. Rev. Inst. Med. trop, Säe Paulo, 28:364-367, 1986

intradermoreaçäo de esporotriquina: negativa; PPD: nódulo de $5 \mathrm{~mm}$; intradermoreaçäo à levedurina: nódulo de $10 \mathrm{~mm}$; intradermoreaçăo variedase: nódulo de $5 \mathrm{~mm}$; intradermoreaçāo à tricofitina: nódulo de $8 \mathrm{~mm}$; glicemia: normal.

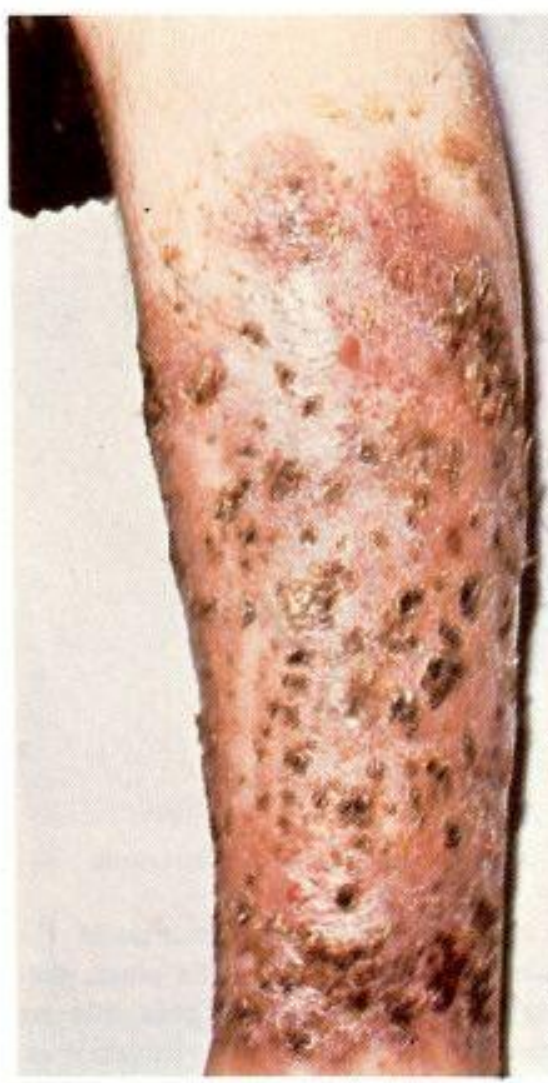

Fig. 1 - Aspecto da lesâo antes do tratamento

Exame micológico direto da lesão (KOH): positivo para pseudofilamentos de levedura.

Cultura em ágar fubá + Tween 80: positivo para clamidosporos $=$ Candida albicans.

Exame histopatológico da lesão cutânea: Fragmento de pele com hiperqueratose e paraqueratose, hipo e hipergranulose, acantose irregular, discreta hiperplasia da epiderme, es. pongiose, vacuolização focal da epiderme. A derme superior apresenta formaçāo de microabscessos e áreas de necrose afetando epiderme com denso infiltrado linfo-histioplasmocitário. Pesquisa de fungos pelo PAS resultou negativa. Processo inflamatório crônico inespecífico com formação de microabscesso (Fig. 2).
Pesquisa de anticorpos anti Candida albi. cans - Fixação de complemento (micrométodo) $=1 / 16$ em 01.03.84 e negativo em 19.04.85, após a cura. Reaçōes de imunodifusão e contra imunoeletroforese negativas (Laboratório de Mico-Sorologia do Instituto de Medicina Tropical de São Paulo - Serviço do Prof. Car. los da Silva Lacaz).

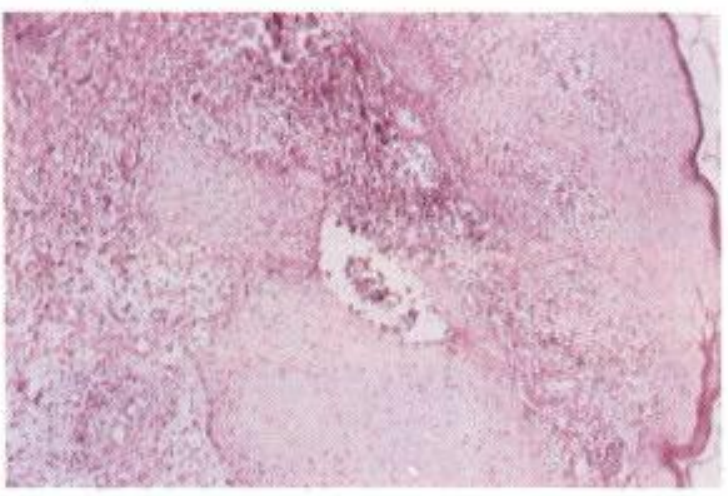

Eig. 2 - Exame histopatológico da lesăo cutănea. $(100 \mathrm{x})$

Inoculou-se $0,2 \mathrm{ml}$ da cultura de Candida albicans em suspensão salina, isolada da própria paciente, na veia marginal da orelha de coelho branco adulto, pesando $4 \mathrm{~kg}$, com sacrificio do animal no 7.0 dia após a inoculaçăo.

Exame micológico direto $(\mathrm{KOH})$ do rim do coelho: positivo para pseudo-filamentos de levedura.

Exame histopatológico do rim do coelho: parênquima renal com focos de exsudação neutrofilica e restos celulares em meio ao qual se observam hifas de fungos, melhor evidenciadas ao PAS; alargamento fibroso do intersticio renal e tubulos dilatados, e por vezes com cilindros hemáticos na sua luz (Figs. 3 e 4).

\section{Evolução}

A paciente foi submetida à terapêutica com Ketoconazol $400 \mathrm{mg}$ ao dia por 30 dias, sendo a dose reduzida para $200 \mathrm{mg}$ ao dia durante o segundo mês de tratamento, tendo apresen. tado regressăo total da lesåo e negativação dos titulos de anticorpos anti Candida albicans (fixação de complemento), não tendo apresentado recidiva do quadro durante o periodo de 
CUGE, L. C.: BEt.DA JUNIOR, W. \& SAI.rBIAN, A. - Candidose ulicero-vegotante da perna. Rev. Inst. Med. trop. Răe Paulo, 28:364-367, 1966.

um ano e meio de seguimento ambulatorial (Fig. 5) .

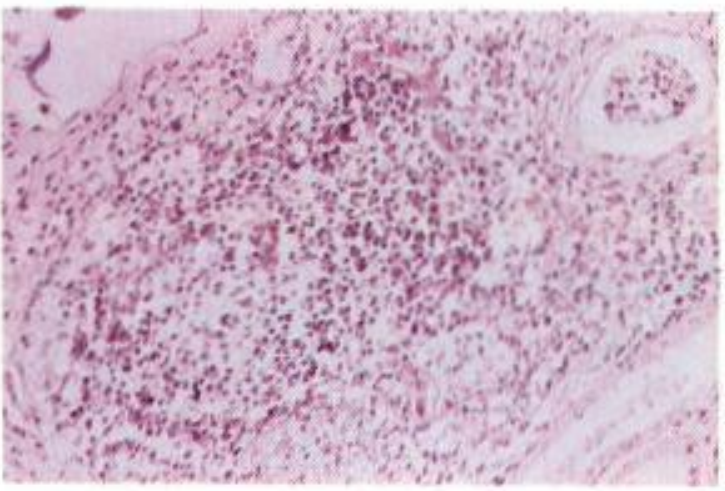

Fig 3 - Exame histopatologico do tim do coelho. (Hematoxilina-eosina $-100 \mathrm{x}$ )

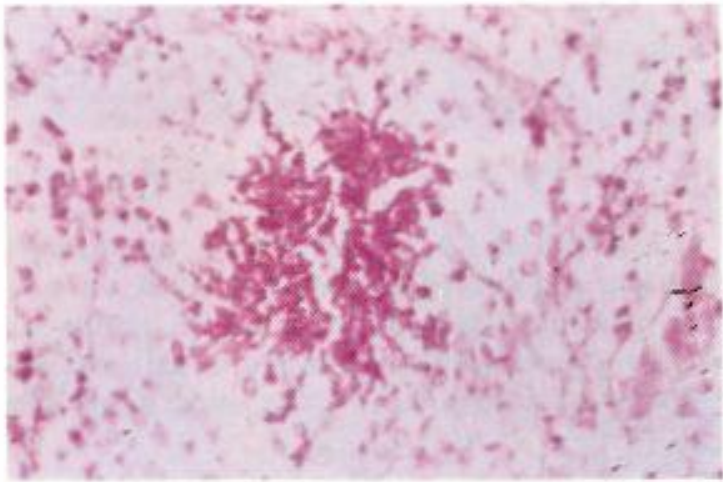

Fig. 4 - Exame histopatoldgico do rim do coelho. (PAS - $100 \times$ )

\section{COMENTARIOS}

O caso apresentado mostra alguns fatos novos em relação à candidiase cutânea na sua forma úlcero vegetante. Primeiramente por ter a doença se íniciado em paciente idosa. Outra fato é que a lesảo ficou localizada, restrita à perna da paciente, a qual năo apresentava nenhuma outra manifestaçăo tegumentar de candidiase, bem como nenhum sinal clínico laboratorial de envolvimento visceral. Sob o ponto de vista imunológico a doente se comportou como fonte reatora, como a maioria das intra. dermoreaçōes demonstrou.

A reaçăo de fixação de complemento com baixo titulo (1/16) também é um dado que reforça forma localizada da doença. Finalmente, a localizaçăo da placa granulomatosa também

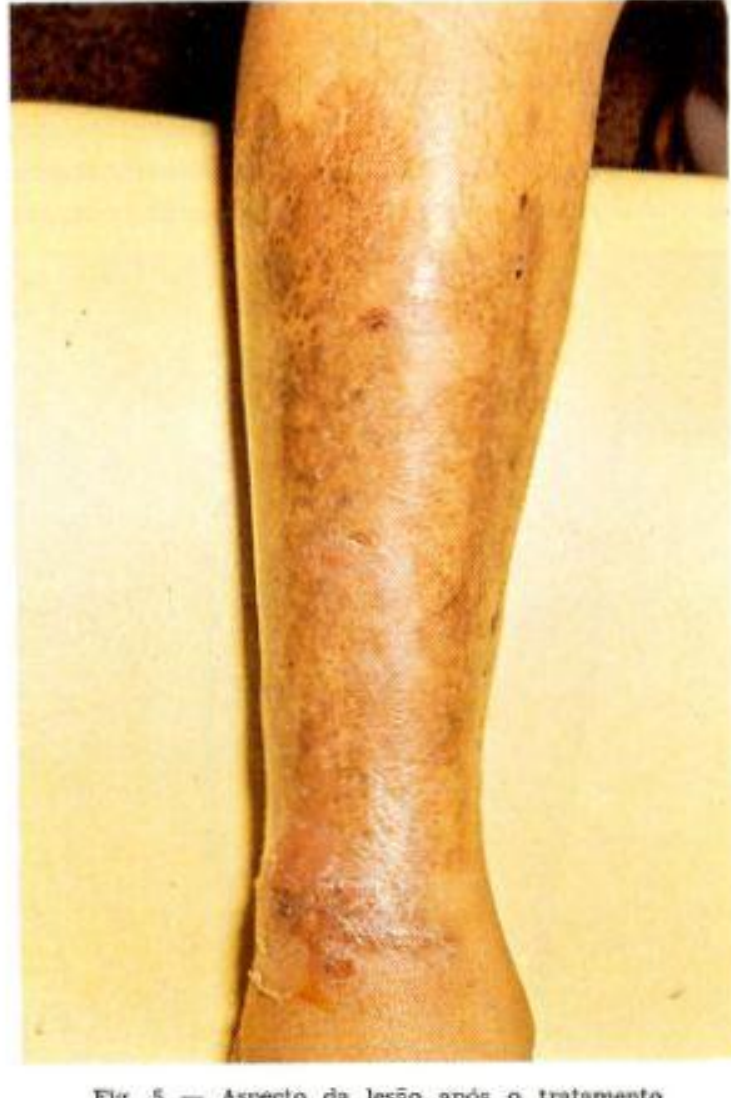

Fig. 5 - Aspecto da lesāo após o tratamento

é um dado que reforça forma localizada da doença. Finalmente, a localizaçắo da placa gra. nulomatosa também foi anômala, pois que as áreas comumentes afetadas como intertrigos, mucosas, face, etc., estavam poupadas.

Entretanto, este caso não deixou nenhuma dúvida diagnóstica, pois os exames clínico-la boratoriais e a resposta terapêutica especifica foram conclusivas.

\section{SUMTIARY}

Vegetant ulcer of the leg by Candida albicans

A case of ulcerative and vegetative cutaneous candidiasis as a single lesion, localized on the inferior third of right leg is presented

This type of manifestation determined by C. albicans is unnusual. This agent was isolated and idenitfied "in vivo" and "in vitro", and the anti-C. albicans antibody title was determin. ed and identified "in vivo" and "in vitro", and dose of the Ketoconazole treatment in the first 
CUCE, L. C.; BELDA JUNIOR, W. \& SALEBIAN, A. - Candidose ülcero-vegetante da perna. Rev. Inst. Med. trop. São Paulo, 28:364-367, 1986.

month which was reduced to $200 \mathrm{mg}$ daily dose in the second month. The lesion cured completely without its posterior relapse. The anti C. albicans antibody became negative.

\section{REFERENCIAS BIBLIOGRAFICAS}

1. DOBIAS, B. - Moniliasis in pediatrics. J. Dis Child., 94: 234-251, 1857.

2. DRAVE, T. E. \& MAIBACH, H. I. - Cutaneous candidiasis. In: ROBINSON JR., H. M. - The diagnosis and treatment of fungus infections. Springfields, Charles C. Thomas, 1974, $n$ 5.28.

3. KATZ, M. E. \& CASSILETH, P. A. - Disseminated candidiasis in a patient with acute leukemia. Successfull treatment with miconazole. J. Amer. med. Ass., 237: 1124-1125, 1977.
4. LACAZ, C. S. - Candidíases. São Paulo, E.P.U.; EDUSP, 1980 .

5. LOURLA, D. B.; STIFF, D. P. \& BENNETT, B. Diisseminated moniliasis in the edult. Medicine, 41: 307-337, 1962.

6. MESER, J. \& FRETER, R. - Effects of antibiotics on susceptibility to oral infection with Candida albicans. Bact. Proc., 60: 98-101, 1960.

7. NEWCOMER, V. D.; LANDAU, J. W.; LEHMAN, R.; DABROWA, N. \& FUJWARA, A. - Candida granuloma. Arcb. Derm., 98: 149-161, 1966.

8. SEELIG, M. S. - The role of antiblotic in the patho genesis of candida infections. Amer. J. Med., 40: 887 $891,1966$.

9. WINNER, H. I. \& HURLEY, R. - Candida alblcans London, J. \& A. Churchill, 1964. p. 306.

Recebido para publicaçăo em 29/08/85. 